\title{
A Panoramic Study of the Dissimilar Morphology of Mandibular Condyle in a Sample of Population in Erbil City
}

\author{
Taha Hama Ahmed ${ }^{1 *}$, Khurshid Abubakir Kheder Khrwatany ${ }^{2}$, Farman H. Shekhani ${ }^{3}$ \\ ${ }^{1}$ Board candidate of maxillofacial surgery (KBMS), Iraq \\ ${ }^{2}$ Trainer and director of erbil center in kurdistan board of medical speciality (KBMS), Iraq \\ ${ }^{3}$ Trainer in kurdistan board of medical speciality (KBMS), Iraq
}

\author{
*Corresponding Author: Taha Hama Ahmed, Board candidate of maxillofacial surgery (KBMS), Iraq, \\ Email: tahaomf@gmail.com
}

\begin{abstract}
The present study aimed to evaluate variation in both size and shape of mandibular condyle in a sample of people in Erbil city as seen on OPGs, which helps to determine popular variants and their relation to side of chewing. This analysis was composed of 100 digital orthopantomograms taken for routine investigation to assess the morphology of 200 condylar heads. Condylar morphology was classified into four types (oval, bird beak, diamond and crooked finger). Shape, position, space, hight, width, size of condyle were evaluated, In our study the bird-beak shape was the majority in both sides (99 joints 49.5\%) with some dominancy in none-chewing side (51\% of none chewing condyles). Both oval and diamond shapes if regarded as normal shape of condyle, in our study they comprise $37 \%$ only of the total joints involved. Where both bird-beak and crooked-finger shapes comprised 126 joints (63\%).in this study the differences between chewing and non-chewing sides were not significant in hight, width, size and space. effect of chewing leads condylar position to be more anteriorly located this was significant.
\end{abstract}

Keywords: Condyle; Orthopantomograph (OPG); Condyle Dissimilarities; Condyle shape; Condyle size; TMJ Unilateral chewing

\section{AIM}

The present study aimed to evaluate variation in both size and shape of mandibular condyle in a sample of people in Erbil city as seen on OPGs, which helps to determine popular variants and their relation to side of chewing.

\section{INTRODUCTION}

Temporomandibular joint (TMJ) is one of the most complex human body structures and is a vital part of the masticatory system that helps in numerous functions including speaking, chewing and swallowing. The main components of TMJ are: condylar process, glenoid fossa, articular disc (which is positioned between condyle and glenoid fossa) and also the articular eminence (Ulhuq, 2008). The condylar process is the key anatomic part of mandible that is responsible for growth of mandibular bone in both vertical and sagittal directions (Yavan et al., 2019).

Radiographic examination of TMJ structures is necessary for evaluating the abnormalities and bony changes that affect this joint (Al-koshab et al., 2015).
The increasing incidence of temporomandibular disorders (TMD) in recent years make it essential to have a thorough knowledge with understanding the anatomy and morphology of the TMJ for distinguishing normal variant from pathological conditions (Maqbool et al., 2018).Changes in morphology of mandibular condyle may be caused by various causes as infections; trauma; tumors; condylar hyperplasia and ankyloses (Anisuzzaman et al., 2019).

Morphologic changes of mandibular condyle occur due to developmental variations, remodeling, different diseases, trauma, endocrine disturbances and radiotherapy. Many studies have evaluated the morphology of the mandibular condyle and reported variation in the shape of condyle. Such changes in morphology may happen throughout the life in response to functional loading. Most of morphologic changes were detected inelderly people due to joint degenerative changes (Park etal., 2014).

The complex structure of the TMJ and localization makes radiographic examination to 
be difficult, and accurate diagnosis requires several types of radiographic images (Tassoker etal., 2017).

Among variable imaging techniques used for imaging of TMJ, orthopantomograph (OPG) radiographs are still considered as the main screening modality for TMJ abnormalities. It is considered to be the most common radiographic technique that was prescribed and interpreted by dental specialists (Sonal et al., 2016). It also has an accepted cost benefit relationship and when compared to computed tomography, the radiation exposure dose is relatively low (Habets et al., 1989).

Honda et al. (1994) has reported that panoramicradiography was useful for detecting TM disorders, in particular in patients with osseous changes or flattening.

Regarding the factors involved in mandibular condyle growth, In addition to identified factors that affecting the growth of mandible condyle like Sox9, type II collagen, PTHrP, Ihh, FGFR, type $\mathrm{X}$ collagen, VEGF, Cbfa1/Runx 2 and OPG/RANKL play a pivotal role in growth and development of mandibular condyle. (Yanqi Yang, Chong Ren, Orthodontics, Faculty of Dentistry, the University of Hong Kong, China), the function has significant role too.

In functional effect on size and volume of condyle; the use of bite-blocks decreased the length of the condylar process $(\mathrm{P}=0.001)$ as well as the volume of the condylar neck $(\mathrm{P}=$ $0.001)$ and head $(P=0.006)$. The soft diet decreased the volume of the condylar neck $(\mathrm{P}<$ $0.001)$ and head $(\mathrm{P}<0.001)$ two to three times more than the bite blocks but did not affect the condylar process length. (Balazs J. Denes1, Benjamin Lazzarotto1, $\$$, Andrea Bresin2).TMJ has many features both anatomically and functionally which make it unique among other human body joints (Math ew et al., 2011). Many studies have to evaluated the appearance of the human condyles and coronoid process and sigmoid notch (Sahithi et al., 2016).

Various classifications were produced for condylar morphology. Many studies have classified condyle into round, angle, convex and flat (Sahithi et al.; Nagaraj et al.,2017; Tassoker et al.; Derwich et al., 2020), most of these studies have used CBCT. Other studies used a nearly similar classification to the previous one, where condyle was classified into round, angle, pointed and flat (Oliveira et al, 2009).
The present study uses the classification of suggested by Aqeel Al Saedi that include oval; bird-beak; diamond and crooked-finger, who used OPG in their study (AqeelAL-Saedi).

In unilateral chewing the mandibular condylar height, ramal height, and ramal plus condylar height on the crossbite side were statistically significantly lower than those on the noncrossbite side. (Kristina Lopatiene** Karolina Trumpyte**)

In measuring mandibular condyle there are many methods e.g in Analysis of height and width of mandibular condyle and of the articular eminence with and without clicking using TMJ radiography by (CekDara Manja1, DaashintaRajaday).

\section{Material AND MethodS}

In this retrospective study, 100 OPGs were selected from the data base of Nova Dental Center radiology unite in Erbil city, to evaluate 200 mandibular condyles. The inclusion criteria were any patient older than 20 years old, condylar head clearly visible on both sides, missing of all molar teeth of one arch or both unilaterally.

All OPGs were taken by Gendex digital panoramicx-ray machine (2014) operating at (10) $\mathrm{mA},(70) \mathrm{Kv}$ and (12 ) seconds exposure time, manufactured by PaloDEx Group OyNahkelantie 180 Fl-04300 TUUSULA, Finland. Patient positioning done according to manufacture's guidelines and mounted head positioning tools.

The exclusion criteria were history of recent trauma inthe maxillofacial region, fully edentulous patients, bilateral posterior edentulous arch, visible tumors and ankylosis, radiographic technique errors.

To evaluate morphology of the condyle head, we used the classification suggested by Chaudhary et al. (2015), which includes four shapes:

Type I: Oval; Type II: Bird-beak; Type III: Diamond and Type IV: Crooked-finger (Fig. 1).

To determine the condylar size, utilizing the CekDaraManja, Daashinta Rajaduray 2019 as a basis, we suggested our own technique of measurement using the installed software and calibration tools. The measurement will be in millimeter. Four points to be determined: superior (the most superior visible point of the 
superior surface of condyle; inferior: midpoint of a line connecting the anteriroposterior out borders of the most narrow part of the neck; anterior and posterior: two point connected by a line drown $5 \mathrm{mms}$ and parallel to the neck line. Points were abbreviated as S: superior; i: Inferior; A: anterior; P: posterior; $\mathrm{n} 1$ : anterior neck; n2: posterior neck (Figure 2).
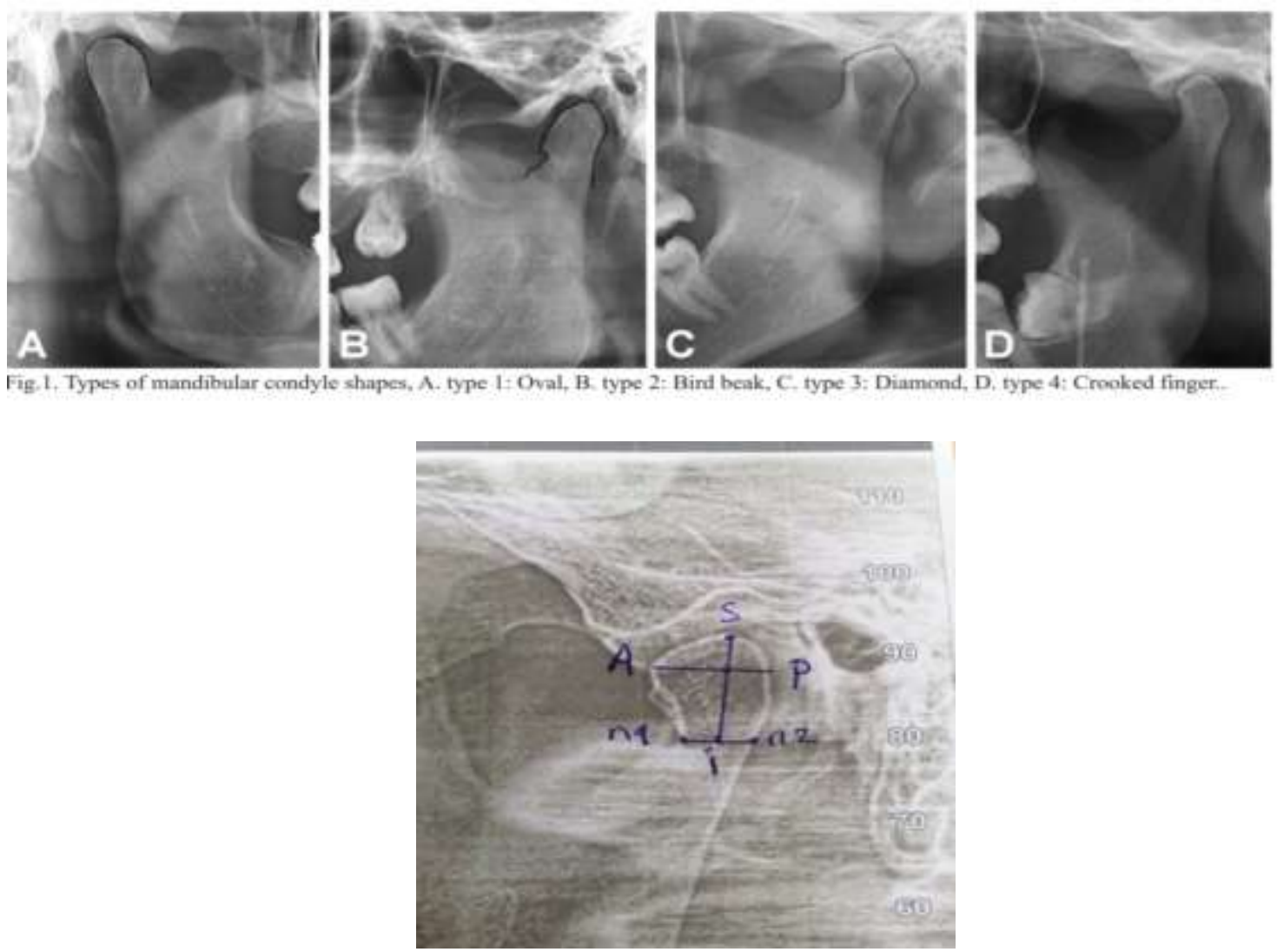

Fig2

To determine unilateral chewing, we selected patients with absence of upper and/or lower molars with no restoration by implants or bridges and dentures.

For the statistical analysis of the data, we have planned to make special Excel sheet for data collection that includes biographic data, right condyle parameters, left condyle parameters including shape and size of condylar head.

The SPSS program was used as software. Pearson Chi Square and T-test was used as statistical test. P-values 0.05 was set as a value of significance.

\section{Results}

Digital OPGs of 100 patients (49 male and 51female; 100 chewing and 100 none-chewing sides) has been included in the present study. The age range was between 24-75 years with mean age of 48.74 year.

As it is shown in the (table1) the mean heights were 11.3 and 11.4; mean width: 10.27 and 10.12; mean sizes 116.68 and 116.364 ; mean spaces are 2.9 and 2.88 , for chewing and nonchewing sides respectively. All were with none significant $\mathrm{p}$-value.

Tabel1. Comparision between the chewing and non-chewing sides

\begin{tabular}{|c|c|c|c|c|}
\hline & Mean & Std. Deviation & p-value & T-test \\
\hline Height of chewing side & 11.32 & 2.22 & \multirow[t]{2}{*}{0.363} & \multirow[t]{2}{*}{ Non-significant } \\
\hline Height of non-chewing side & 11.44 & 2.06 & & \\
\hline Width of chewing side & 10.27 & 1.62 & \multirow[t]{2}{*}{0.248} & \multirow[t]{2}{*}{ Non-significant } \\
\hline Width of non-chewing side & 10.12 & 1.40 & & \\
\hline Size of chewing side & 116.68 & 31.44 & \multirow[t]{2}{*}{0.854} & \multirow[t]{2}{*}{ Non-significant } \\
\hline Size of non-chewing side & 116.36 & 27.77 & & \\
\hline Space of chewing side & 2.90 & 1.54 & \multirow[t]{2}{*}{0.907} & \multirow[t]{2}{*}{ Non-significant } \\
\hline Space of non-chewing side & 2.88 & 1.56 & & \\
\hline
\end{tabular}


The evaluation of shape of condyles (table 4) revealed that there were 32 and 23 oval; 48 and 51 bird- beak; 9 and 18 crooked-finger; and, 11

Tabel2. Shape of non-chewing side * Shape of chewing side

\begin{tabular}{|l|c|c|c|c|c|c|}
\hline \multicolumn{2}{|c|}{ Shape of chewing side } \\
\hline \multirow{3}{*}{ non-chewing side } & oval & Bird beak & Crooked finger & diamond & Total \\
\cline { 2 - 8 } & bird beak & 13 & 4 & 0 & 6 & 23 \\
\cline { 2 - 8 } & crooked finger & 6 & 40 & 0 & 1 & 51 \\
\cline { 2 - 8 } & diamond & 3 & 2 & 9 & 1 & 18 \\
\hline \multicolumn{1}{|l|}{ Total } & 32 & 48 & 9 & 3 & 8 \\
\hline
\end{tabular}

About the position of condyle in relation to glenoid fossa, the study (in table 3 ) showed that there are 66 middle and 34 anteriorly positioned

and 8 diamond shaped condyles for chewing and non-chewing sides respectively.

Tabel3. Position of non-chewing side * Position of chewing side

\begin{tabular}{|l|l|l|l|l|}
\hline \multicolumn{5}{|c|}{ Position of chewing side } \\
\hline \multicolumn{2}{|c|}{} & anterior & middle & Total \\
\hline Non-chewing side & anterior & 24 & 10 & 34 \\
\cline { 2 - 5 } & middle & 18 & 48 & 66 \\
\hline Total & 42 & 58 & 100 \\
\hline
\end{tabular}

\section{DISCUSSION}

Chewing as a process exerts significant load on TMJ. The tissues of joint are adapted to this kind of function. This is does not mean they can tolerate over or under function load. Theoretically, absence of posterior teeth, means absence of stoppers and distributers of mastication forces. The whole force of masseter and middle pterygoid muscles will be transferred to the joint. In reality the nonechewing side will be the side of hypofunctioning, since muscles of mastication are voluntary, they're going to have minimum contraction on that side which by time may lead to loss of contraction power. However possibly there going to be stretching force toward the chewing side since there is no interdigitation of posterior teeth that works as localizer. Such stretching of none-chewing side may be carryout by lateral pterygoid. On the other hand, the person will fully contract muscles on the chewing side for the whole time of eating, which means over loading.

In our study the bird-beak shape was the majority in both sides (99 joints 49.5\%) with some dominancy in none-chewing side (51\% of none chewing condyles). This finding is not matching what was published by (Aqeel AL saedi) where, in a sample of people from Basrah city, they found that oval shape was the most common $(56 \%)$ in all age groups in males and female followed by type 3 (diamond), type 2 (bird-beak) and finally type 4 (crooked-finger).
The oval shaped in our study were 55 joint (27.5\%) only. Perhaps the selection criteria of OPGs in our study had played role to make such mismatching data. In our study we intentionally selected those with one side none-chewing to see the effect of hypofunctionality (nonechewing) on the shape of condyle. The dominancy of bird-beak shape in both sides and especially in none-chewing side may explain that phenomena.

Both oval and diamond shapes if regarded as normal shape of condyle, in our study they comprise $37 \%$ only of the total joints involved. Where both bird-beak and crooked-finger shapes comprised 126 joints (63\%). We are explaining this as the effect of hyper and hypo functionality on the shape of condyle in accordance with chewing and none-chewing habits. These abnormal appearance of condyle in clinical and radiological point of view has been attributed to osteoarthritic changes in TMJ. (Miles 2016, Priyadarshini Karthikeyan 2019) Hence, the dominancy of above mentioned shaped may be attributed to some phases of osteoarthiris in cases with unilateral chewing. What is important to be noticed here is the fact that both sides can be affected, one because of low functionality and the other due to over loading.

Despite the fact that in the study by (Balazs J. Denes1, $\$$, Benjamin Lazzarotto1, $\$$, Andrea Bresin2), using of bite-blocks and soft diet authors confirmed their effect on the condylar 
neck and head size, but in this study the differences between chewing and non-chewing sides were not significant (height, width and space).

In condylar position there was a significant difference between chewing and non-chewing sides, in chewing side condyles mostly located in middle (58\%) while in non-chewing side more condyles located in middle $(66 \%)$, in other hand anteriorly positioned condyle was seen more in chewing side (42\%) than the nonchewing sides (34\%) as a result we can say effect of chewing leads condylar position to be more anteriorly located this may be due to more load and produce distructive force on condyle in chewing side (as a compensatory to other side which is non-chewing) with subsequent increase laxity inretrodiscal tissue and ligaments which connect condyle to temporal bone so finally causes the condylar position to be anteriorly located, this supported by (Hodges;mandibular condyle movement during unilateral biting 2002).

\section{CONCLUSiON}

The present study aimed to evaluate variation in morphology of mandibular condyle in a sample of people in Erbil city as seen on orthopantomographs (OPGs), which showed any significance to their relation to side of chewing, in which condylar hight, width, size and space of joint are non-significant but shape and position are significant. Further studies on Erbil city is needed especially using CBCT to detect changes in size and morphology in relation to chewing and non-chewing side.

\section{REFERENCES}

[1] Miles, D. (2016). "Cone Beam Imaging and Condyles: From Rorschach Tests to Reality." 16-20.

[2] Priyadarshini Karthikeyan, L. P. H., Koh Pei Yen, Lau Wen Weng, Ramesh Kumaresan. (2019). "Prevalence of various morphological types of Condyle seen among Malaysian Ethnic groups using Conventional Orthopantomogram." Medical Science 23(100): 869-875.

[3] Aqeel AL-saedi panoramic study of the morphology of mandibular condyle 2020.

[4] Balazs J. Denes $1, \$$, Benjamin Lazzarotto1, Andrea Bresin2 (Effect of different masticatory functional demands on the 3D mandibular condyle morphology of growing rats using posterior bite-blocks).

[5] (R Kristina Lopatienë*, Karolina Trumpytè) relationship between unilateral posterior crossbite and mandibular asymmetry during late adolescence.

[6] Al-koshab et al., 2015. Assessment of Condyle and Glenoid Fossa Morphology Using CBCT in South-East Asians.

[7] Yavan et al., 2019. Evaluation of condylar structures on panoramic radiographs in adolescent patients with celiac disease

[8] Anisuzzaman et al., 2019.evaluation of mandibular condylar morphology by OPJ in bangilsdish populations.

[9] CekDara Manja1, Daashinta Rajaday. Analysis of height and width of mandibular condyle and shape of the articular eminence with and without clicking using TMJ radiography 2019.

Citation: Taha Hama Ahmed, Khurshid Abubakir Kheder Khrwatany, Farman H. Shekhani. "A Panoramic Study of the Dissimilar Morphology of Mandibular Condyle in a Sample of Population in Erbil City". ARC Journal of Dental Science. 2021; 6(2):1-5. DOI: https://doi.org/10.20431/2456-0030.0602001.

Copyright: () 2021 Authors. This is an open-access article distributed under the terms of the Creative Commons Attribution License, which permits unrestricted use, distribution, and reproduction in any medium, provided the original author and source are credited. 